\title{
GAYA HIDUP, KONSUMSI SUPLEMEN, J AMU, TANAMAN OBAT, DAN STATUS KESEHATAN LANSIA DI KABUPATEN BOGOR
}

\author{
(Life Style, Supplement Consumption, Traditional Medicine ("Jamu"), Medical Plants, and \\ Health Status of Elderly at Bogor District)
}

\author{
Rian Diana ${ }^{1}$, Katrin Roosita ${ }^{2}$, dan Ali Khomsan ${ }^{2 *}$ \\ ${ }^{1}$ Program Studi Gizi Masyarakat dan Sumberdaya Keluarga, Fakultas Pertanian (FAPERTA) IPB. \\ 2 Departemen Gizi Masyarakat, Fakultas Ekologi Manusia (FEMA), IPB \\ Tel: 0251-8628304/8621258; Fax: 0251-8625846/8622276
}

\begin{abstract}
ABST RACT
The objective of this research was to analize the correlation of life style, supplement consumption, traditional medice, medical plants, and health status of elderly at Bogor District. The research was conducted at Ciampea Sub-district, Bogor District, West Java, from J une till December 2005 using cross sectional study design. The sample size was 90 elders ( 45 male and 45 female). The result indicated that $3.7 \%$ sample was smoker, $17.8 \%$ sample had sport habit, and $42.2 \%$ sample had leisure activity. Only $6.7 \%$ sample consumed supplement, meanwhile the consumption of traditional medicine was $53.3 \%$ and medical plants $48.9 \%$ The common diseases were hypertension, rheumatic and gout. The sample had a lot af health complain such as not feeling well, anemia, headache, and loin pain. Based on blood pressure measurement, $45.5 \%$ sample suffered from hypertension. The elders sport activity was negatively correlated with loin pain $(p<0.05)$, meanwhile supplement consumption was positively correlated with constipation $(p<0.01)$. Traditional medicine had a positive correlation with age $(p<0.01)$ and negative correlation with loin pain $(p \varangle 0.05)$. Medical plants had a positive correlation with decreased appetite $(p<0.01)$, chewing difficulties $(p<0.01)$ and decreased sense of smell $(p<0.01)$.
\end{abstract}

Keywords: elderly, health status, supplement, traditional medicine, medical plants

\section{PENDAHULUAN}

Berdasarkan deklarasi yang telah dimaklumat oleh Badan Organisasi Kesehatan Dunia (WHO) pada tahun 1978, telah dinyatakan bahwa tahun 2000 ditetapkan sebagai tahun kesehatan untuk semua. Tingkat kesehatan kelompok usia lanjut dapat digunakan sebagai tolak ukur tingkat kesehatan masyarakat pada umumnya. Semakin banyak jumlah penduduk kelompok tua maka dapat dikatakan bahwa tingkat kesehatan masyarakat tersebut semakin baik (Mursito, 2004). Data SUSENAS tahun 2004 menunjukkan bahwa penduduk Jawa Barat berjumlah 38,472,185 jiwa, dari jumlah tersebut $14.5 \%$ (5,598,251 jiwa) adalah lansia. Dari jumlah tersebut sebanyak $48.8 \%$ wanita dan $51.2 \%$ pria (BPS, 2004).

Kondisi tubuh yang mulai menurun merupakan bagian dari proses penuaan. Penuaan terbagi dua yaitu penuaan eksternal yang

\footnotetext{
* Penulis untuk korespondensi, Departemen Gizi Masyarakat, FEMA, IPB; Tel: 0251-8628304/8621258: Fax: 0251-8625846/8622276

Email: erlangga259@yahoo.com
}

umumnya dapat dilihat dari perubahan yang terjadi pada kulit, rambut, gigi, dan lain-lain, sedangkan perubahan pada bagian dalam tubuh disebut penuaan internal. Penuaan yang terjadi pada masa ini akan berpengaruh terhadap masalah gizi dan kesehatan. Aspek kesehatan yang perlu diwaspadai oleh lansia ialah tekanan darah tinggi. Hal ini sejalan dengan aspek degeneratif yang muncul pada lansia. Gaya hidup, konsumsi pangan, suplemen, obat-obatan, jamu, dan tanaman obat turut berperan dalam menentukan kesehatan lansia.

Penelitian ini bertujuan untuk mengetahui hubungan gaya hidup, konsumsi suplemen, jamu, dan tanaman obat dengan status kesehatan lansia di Kabupaten Bogor.

\section{METODE PENELITIAN}

\section{Desain, Tempat, dan Waktu Penelitian}

Penelitian ini merupakan bagian dari penelitian payung yang berjudul Studi tentang Kualitas Hidup Lansia: Tinjauan Aspek Sosial Ekonomi, Konsumsi Pangan, Gaya Hidup, Status Gizi, dan Kesehatan. Penelitian ini meng- 
gunakan desain cross sectional study. Lokasi penelitian dilakukan secara purposive dengan pertimbangan kemudahan akses, yaitu Kecamatan Ciampea, Kabupaten Bogor. Selanjutnya dipilih secara acak 2 desa sebagai lokasi penelitian, yaitu Desa Tegalwaru dan Cinangka. Penelitian ini dilaksanakan pada bulan Juni hingga Desember 2005.

\section{Penarikan Contoh}

Contoh penelitian adalah lansia dengan kriteria berusia lebih dari 60 tahun, bugar, tidak bungkuk, dapat diukur tinggi dan berat badannya, tidak mengalami gangguan pendengaran serta bersedia dan dapat diwawancarai. Jumlah contoh seluruhnya 90 orang (45 pria dan 45 wanita) dan dipilih secara acak dari desa lokasi penelitian.

\section{Jenis dan Cara Pengumpulan Data}

Jenis data yang digunakan adalah data primer, yang meliputi karakteristik sosial ekonomi, gaya hidup, pola konsumsi suplemen, jamu, tanaman obat, dan status kesehatan (tekanan darah dan keluhan kesehatan). Data primer diperoleh dengan cara wawancara menggunakan kuesioner yang dibacakan kepada contoh. Data konsumsi suplemen, tanaman obat, dan keluhan kesehatan dikumpulkan dengan metode recall satu bulan terakhir. Data tekanan darah diukur dengan tensimeter yang dilakukan oleh tenaga medis.

\section{Pengolahan dan Analisis Data}

Data yang telah terkumpul diverifikasi dan diolah menggunakan Microsoft Excell dan SPSS version 11.5 for Windows, kemudian dianalisis secara deskriptif dan inferensia. Berdasarkan JNC VII (2003), tekanan darah dikategorikan menjadi 3 yaitu normal $(<120 / 80$ $\mathrm{mmHg}$ ), prehipertensi 120-139/80-89 mmHg), dan hipertensi $\geq 140 / 90 \mathrm{mmHg}$. Tahap hipertensi dibagi menjadi 2 yaitu Tahap 1 (140$159 / 90-99 \mathrm{mmHg})$ dan Tahap $2(\geq 160 / \geq 100$ $\mathrm{mmHg}$ ).

\section{HASIL DAN PEMBAHASAN}

\section{Karakteristik Contoh}

Berdasarkan usianya, lebih dari separuh contoh (64.4\%) berusia antara 60-70 tahun. Menurut tingkat pendidikannya, sebagian besar contoh (76.7\%) tidak pernah mendapatkan pendidikan formal. Lebih dari separuh contoh masih bekerja (54.4\%). Jenis pekerjaannya antara lain petani, pengrajin anyaman, buruh tani, dan pedagang. Sebagian besar contoh (80\%) mempunyai jumlah anggota keluarga 2-6 orang. Dalam memenuhi kebutuhan seharihari, lansia banyak dibantu oleh kerabat atau keluarganya. Darmojo (2000) mengemukakan bahwa lansia Indonesia masih banyak tergantung pada orang lain (terutama anaknya). Bantuan dari keluarga ini meliputi semua bidang baik finansial, makanan, pakaian, bantuan fisik dan moral.

Dari sisi pendapatan, sebagian besar contoh (77.8\%) berpendapatan <Rp. 69,420/ kap/bulan (miskin). Dari sisi pengeluaran kurang dari separuh contoh (45.5\%) memiliki pengeluaran antara Rp. 100,000/kap/bulan - Rp. 300,000/kap/bulan. Kesenjangan antara pendapatan dan pengeluaran dapat terjadi karena contoh mendapatkan bantuan secara finansial dari keluarganya untuk memenuhi kebutuhan sehari-hari.

\section{Gaya Hidup}

\section{Aktivitas Sehari-hari}

Sebanyak 42.2\% contoh mempunyai tingkat aktivitas yang ringan seperti duduk-duduk, mengobrol, mengunjungi cucu, kegiatan keagamaan, dan berolahraga. Sebesar 18.9\% mempunyai aktivitas sedang, sedangkan sisanya sebanyak $38.9 \%$ contoh mempunyai aktivitas yang berat seperti bekerja di sawah, buruh bangunan, dan pengrajin anyaman. Rata-rata waktu yang digunakan untuk tidur adalah 7.9 jam, istirahat (duduk-duduk, bersantai dan waktu senggang) 6.1 jam, dan ibadah sebanyak 1.5 jam.

\section{Kebiasaan Olahraga}

Sebagian besar (82.2\%) contoh tidak terbiasa berolahraga dengan alasan tidak adanya sarana olahraga, tidak sempat/bekerja, dan sudah tidak kuat. Hanya sebagian kecil (17.8\%) contoh yang mempunyai kebiasaan berolahraga. Jenis olahraga yang banyak dilakukan adalah jalan dan menggerakkan badan, lari kecil, dan senam pernafasan. Frekuensi olahraga yang dilakukan contoh yaitu antara > 3x/ minggu (37.6\%) dan 2-3x/minggu (31.3\%). Rata-rata lama olahraga yang dilakukan contoh adalah 45.3 menit. Oswari (1997) menyatakan bahwa latihan yang sesuai untuk lansia adalah gerak jalan, senam, yoga, dan berlari-lari kecil (jogging). Frekuensi latihan lebih baik jika dilakukan 4-5 kali dalam seminggu, paling sedikit 3 kali dalam seminggu, karena setelah 48 jam daya tahan tubuh seseorang akan menurun, sebelum menurun sudah harus berlatih lagi. Agar mendapat pengaruh baik untuk jan- 
tung dan peredaran darah sebaiknya berlatih sampai mencapai sasaran latihan denyut nadi (109-132 kali per menit) selama 20-45 menit. Latihan yang kurang dari 20 menit kurang bermanfaat.

\section{Konsumsi Alkohol}

Seluruh contoh tidak ada yang mengonsumsi minuman beralkohol. Alasan utama yang dikemukakan adalah alasan keagamaan (bertentangan dengan ajaran agama).

\section{Kebiasaan Merokok}

Lebih dari separuh contoh (63.3\%) tidak merokok. Sisanya (36.7\%) memiliki kebiasaan merokok. Kebiasaan ini sulit dihilangkan karena contoh sudah mengonsumsi rokok selama 41-60 tahun. Lebih dari setengah contoh $(57.6 \%)$ yang merokok termasuk dalam perokok ringan (1-10 batang/hari). Sebanyak $39.4 \%$ perokok sedang (11-20 batang/hari), dan hanya sebagian kecil contoh (3\%) yang termasuk dalam kategori perokok berat ( $>20$ batang/ hari).

\section{Suplemen}

Hanya sebagian kecil contoh (6.7\%) yang mengonsumsi suplemen. Sebanyak $66.6 . \%$ contoh yang mengonsumsi suplemen dengan frekuensi jarang. Setengah dari contoh yang mengonsumsi suplemen hanya mengeluarkan uang sebesar < Rp. 5,000/bulan untuk mengonsumsi suplemen. Jenis suplemen yang paling banyak dikonsumsi adalah suplemen yang berkhasiat untuk melancarkan buang air besar seperti suplemen serat dan minyak ikan. Menurut Wirakususmah (2000) konstipasi merupakan keluhan umum yang dirasakan lansia. Pencegahan yang dapat dilakukan oleh lansia adalah mengonsumsi serat, cairan dan atau berbagai suplemen.

\section{Цamu}

Lebih dari separuh contoh (53.3\%) mengkonsumsi jamu. Jenis jamu yang banyak dikonsumsi adalah jamu kemasan modern (64.9\%) dan jamu gendong (35.1\%). Sebagian besar contoh mengonsumsi jamu untuk tujuan promotif dan kuratif. Tujuan promotif dimaksudkan untuk menyegarkan atau menyehatkan badan $(31.3 \%)$ dan menambah nafsu makan $(14.6 \%)$, sedangkan tujuan kuratif untuk mengobati pegel linu (31.3\%).

\section{Tanaman Obat}

Kurang dari separuh contoh (48.9\%) mengonsumsi tanaman obat. Jenis tanaman obat yang digunakan contoh berjumlah 64 jenis. Sebanyak $32.2 \%$ contoh memiliki pekarangan tanaman obat dengan 4-10 jenis tanaman obat $(51.7 \%)$ dan < 4 jenis tanaman obat (48.3\%). Bagian tanaman obat yang banyak digunakan contoh adalah daun (44.1\%), rimpang $(17.6 \%)$, dan akar (11.8\%). Contoh memperoleh tanaman obat dengan cara diberi orang lain (36.8\%), memperoleh sendiri dari kebun atau pekarangan (35.1\%) dan membeli (8.1\%). Informasi mengenai tanaman obat diperoleh contoh lebih dari satu sumber yaitu dari orang tua dan tetangga $(27.8 \%)$, mengetahui sendiri $(16.7 \%)$, selebihnya dari orang lain, kerabat, dan media massa. Sebagian besar contoh mengonsumsi tanaman obat untuk tujuan kuratif dan promotif. Tujuan kuratif antara lain untuk keluhan pegel linu (20.5\%), sakit perut $(15.9 \%)$, batuk (11.4\%) dan hipertensi (11.4\%). Tujuan promotif antara lain untuk menambah nafsu makan (15.9\%) dan menyehatkan badan (11.4\%).

\section{Status Kesehatan}

\section{Keluhan Kesehatan}

Penyakit yang banyak diderita oleh contoh adalah hipertensi (38.9\%), rematik (32.2\%) dan asam urat (15.6\%). Proses penuaan yang terjadi baik internal maupun eksternal mengakibatkan timbulnya beberapa penyakit. Mursito (2004) menyatakan bahwa penurunan fungsi dari organ tubuh maupun metabolisme tubuh dapat menyebabkan timbulnya beberapa penyakit. Hadirnya penyakit ini mengganggu kesehatan dan aktivitas.

Tabel 1. Sebaran Contoh berdasarkan Jenis Penyakit

\begin{tabular}{lcc}
\hline \multicolumn{1}{c}{ Jenis Penyakit } & $\mathrm{n}$ & $\%$ \\
\hline Hipertensi & 35 & 38.9 \\
Rematik & 29 & 32.2 \\
Asam Urat & 14 & 15.6 \\
Maag & 7 & 7.8 \\
Asma & 6 & 6.7 \\
Jantung & 5 & 5.6 \\
Hernia & 4 & 4.4 \\
Stroke & 3 & 3.3 \\
Hipotensi & 3 & 3.3 \\
Liver & 2 & 2.2 \\
Ginjal & 2 & 2.2 \\
Lainnya & 6 & 6.7 \\
\hline
\end{tabular}

Lebih dari separuh contoh mempunyai keluhan kesehatan pegel linu, lemah, letih, lesu dan pusing. Lebih dari sepertiga contoh memiliki jenis keluhan nyeri pinggang, gangguan 
penglihatan, kesemutan, dan susah mengunyah. Menurut Mursito (2004), kelompok lansia lebih banyak terkena serangan rematik. Gejala penyakit ini meliputi rasa lelah, kaku pada persendian, ketegangan otot, dan rasa nyeri. Wirakusumah (2000) menyatakan bahwa lemah, letih, lesu merupakan gejala anemia yang sudah sangat umum. Selain itu konstipasi juga sangat umum diderita lansia. Karena gerakan otot pada usus dan aktifitas gastrointestinal semakin menurun dengan bertambahnya usia. Gustatory papillae (bintil perasa) mulai kurang sensitif yang didukung oleh gangguan gigi geligi mengakibakan lansia mengalami hambatan dalam proses pengunyahan, sehingga menyebabkan turunnya nafsu makan.

Tabel 2. Persentase Contoh berdasarkan Jenis Keluhan Selama Satu Bulan Terakhir

\begin{tabular}{lcc}
\hline \multicolumn{1}{c}{ J enis Keluhan } & $\mathbf{n}$ & $\%$ \\
\hline Pegel Linu & 65 & 72.2 \\
Lemah, Letih, Lesu & 51 & 56.7 \\
Pusing & 48 & 53.3 \\
Nyeri Pinggang & 45 & 50.0 \\
Gangguan Penglihatan & 44 & 48.9 \\
Kesemutan & 43 & 47.8 \\
Susah Mengunyah & 33 & 36.7 \\
Dada Sesak/Sesak Napas & 24 & 26.7 \\
Sulit Tidur & 21 & 23.3 \\
Nafsu Makan Menurun & 14 & 15.6 \\
Susah Buang Air Besar & 12 & 13.3 \\
Batuk & 11 & 12.2 \\
Mual & 9 & 10.0 \\
Berkurangnya Indera Penciuman dan & 5 & 5.6 \\
Rasa & 3 & 3.3 \\
Sariawan & 4 & 4.4 \\
Sakit Kaki
\end{tabular}

Hampir semua jenis keluhan kesehatan dirasakan setiap hari. Rata-rata lama keluhan yang dirasakan contoh adalah sepanjang hari. Cara mengatasi berbagai keluhan yang dirasakan adalah dengan cara tidur/beristirahat, dipijit, minum obat waarung, minum jamu, dan lainnya. Sepertiga contoh mengalami keluhan dengan intensitas $\leq 5$ menit setiap kali keluhan tersebut terasa.

\section{Tekanan Darah}

Pada pengukuran tekanan darah sistolik dan diastolik, hampir setengah dari contoh mengalami hipertensi (45.5\%) yang tersebar menjadi hipertensi tahap 1 (20\%) dan hipertensi tahap 2 (25.5\%). Sheps (2005) menyatakan bahwa kebanyakan kasus hipertensi dimulai dengan tekanan darah normal yang berkem- bang menjadi prehipertensi lalu akhirnya menuju hipertensi tahap 1.

Tabel 3. Sebaran Contoh berdasarkan Tekanan Darah Sistolik dan Diastolik

\begin{tabular}{lcc}
\hline \multicolumn{1}{c}{ Kategori Tekanan Darah $(\mathbf{m m H g})$} & $\mathbf{n}$ & $\%$ \\
\hline Normal $(<120 / 80)$ & 20 & 22.3 \\
Prehipertensi $(120-139 / 80-89)$ & 29 & 32.2 \\
Hipertensi $(\geq 140 / \geq 90)$ & & \\
$-\quad$ Tahap $1(140-159 / 90-99)$ & 18 & 20.0 \\
- Tahap 2 $(\geq 160 / \geq 100)$ & 23 & 25.5 \\
\hline \multicolumn{1}{c}{ Total } & 90 & 100.0 \\
\hline
\end{tabular}

Hasil uji korelasi Pearson menunjukkan bahwa usia berkorelasi positif dengan tekanan darah sistolik dan diastolik $(\mathrm{p}<0.01)$. Kiongdo (1997) menyatakan bahwa hipertensi meningkat sejalan dengan meningkatnya usia. Menurut Takasihaeng (2000), hipertensi dengan tekanan sistolik tinggi banyak ditemukan pada mereka yang berusia lanjut. Hal ini erat kaitannya dengan proses penuaan.

\section{Hubungan antar Variabel}

Hasil uji korelasi Spearman menunjukkan bahwa aktivitas sehari-hari, kebiasaan olahraga, kebiasaan merokok, konsumsi alkohol, konsumsi suplemen, jamu dan tanaman obat tidak berkorelasi dengan tekanan darah sistolik dan diastolik. Hal ini dapat disebabkan oleh adanya faktor lain yang sangat menentukan tekanan darah yaitu pola makan (masukan sodium dan kalium).

Hasil uji korelasi Spearman menunjukkan bahwa kebiasaan olahraga contoh berkorelasi negatif terhadap sakit pinggang $(p<0.05)$. Sheps (2005) menyatakan bahwa latihan peregangan setiap hari dapat mengurangi kekakuan otot. Tingkat pendidikan berkorelasi negatif dengan kebiasaan merokok $(p<0.01)$. Menurut Jamal (2006), perilaku merokok berkaitan dengan pengetahuan dan sikap seseorang terhadap rokok, serta pendidikannya.

Konsumsi suplemen berkorelasi postif dengan keluhan susah buang air besar $(p<0.01)$. Wirakusumah (2000) menyatakan bahwa pencegahan konstipasi yang paling mudah adalah dengan meningkatkan konsumsi serat dan cairan dalam diet dan atau mengonsumsi suplemen.

Konsumsi jamu berkorelasi positif dengan usia $(p<0.01)$ dan berkorelasi negatif dengan nyeri pinggang $(\mathrm{p}<0.05)$. Hasil penelitian Gedif dan Hanh (2003) menunjukkan bahwa penggunaan tanaman obat (jamu) meningkat 
dengan bertambahnya usia. Jenis jamu yang banyak dikonsumsi contoh yang mempunyai keluhan sakit pinggang adalah jamu pegel linu. Handayani (2002) menyatakan bahwa lansia yang menderita nyeri sendi dan otot dapat memanfaatkan obat tradisional sebagai pengganti obat modern.

Konsumsi tanaman obat berkorelasi positif dengan menurunnya nafsu makan $(p<0.01)$, susah mengunyah $(p<0.01)$, dan menurunnya indera penciuman dan perasa $(p<0.01)$. Hal tersebut menunjukkan bahwa contoh yang merasa nafsu makannya turun, susah mengunyah, dan menurunnya indera penciuman dan perasa mengkonsumsi tanaman obat untuk mengurangi keluhan kesehatan tersebut. Tanaman obat yang banyak digunakan untuk meningkatkan nafsu makan adalah lempuyang dan kunyit. Mursito (2004) menyatakan bahwa kunyit mengandung kurkumin yang dapat meningkatkan nafsu makan.

\section{KESIMPULAN}

Lebih dari separuh contoh berusia antara 60-70 tahun. Tingkat pendidikan contoh relatif rendah. Lebih dari separuh contoh masih bekerja dan sebagian besar contoh mempunyai jumlah anggota keluarga 2-6 orang.

Kurang dari separuh contoh (42.2\%) memiliki tingkat aktivitas yang ringan. Hanya sebagian kecil contoh $(17.8 \%)$ yang mempunyai kebiasaan berolahraga. Jenis olahraga yang banyak dilakukan adalah jalan kaki dan menggerakkan badan, lari kecil, dan senam pernafasan. Frekuensi olahraga yang dilakukan contoh yaitu >3x/minggu $(37.6 \%$ ) dan $2-3 x /$ minggu (31.3\%). Rata-rata lama olahraga yang dilakukan contoh adalah 45.3 menit. Seluruh contoh tidak ada yang mengonsumsi minuman beralkohol. Sebanyak $36.7 \%$ contoh memiliki kebiasaan merokok. Lebih dari setengahnya termasuk dalam perokok ringan.

Hanya sebagian kecil contoh (6.7\%) yang mengonsumsi suplemen. Sebanyak $66.6 . \%$ contoh yang mengonsumsi suplemen mempunyai frekuensi yang jarang. Setengah dari contoh yang mengonsumsi suplemen hanya mengeluarkan uang $<$ Rp. 5,000/bulan untuk mengonsumsi suplemen.

Lebih dari separuh contoh (53.3\%) memiliki kebiasaan mengonsumsi jamu. Jenis jamu yang banyak dikonsumsi adalah jamu kemasan modern (64.9\%). Sebagian besar contoh mengonsumsi jamu untuk tujuan promotif seperti menyegarkan atau menyehatkan badan (31.3\%) dan tujuan kuratif seperti mengobati pegel linu $(31.3 \%)$.

Kurang dari separuh contoh (48.9\%) memiliki kebiasaan mengonsumsi tanaman obat dengan tujuan kuratif, promotif, dan preventif. Jenis tanaman obat yang digunakan contoh sebanyak 64 jenis. Sebanyak 32.2\% contoh memiliki pekarangan tanaman obat, lebih dari setengahnya (51.7\%) memiliki 4-10 jenis tanaman obat. Bagian tanaman obat yang banyak digunakan contoh adalah daun (44.1\%). Contoh memperoleh tanaman obat karena diberi orang lain (36.8\%), memperoleh sendiri dari kebun/ pekarangan (35.1\%) dan membeli (8.1\%). Informasi mengenai tanaman obat diperoleh contoh lebih dari satu sumber yaitu dari orangtua dan tetangga (27.8\%), mengetahui sendiri (16.7\%), selebihnya dari orang lain, kerabat dan media massa.

Penyakit yang banyak diderita oleh contoh adalah hipertensi (38.9\%), rematik (32.2\%) dan asam urat (15.6\%). Jenis keluhan kesehatan contoh cukup beragam, akan tetapi keluhan yang banyak dirasakan diantaranya pegel linu (72.2\%), lemah, letih, lesu $(56.7 \%)$, pusing $(53.3 \%)$, nyeri pinggang $(50 \%)$, gangguan penglihatan $(48.9 \%)$, kesemutan $(47.8 \%)$, susah mengunyah (36.7\%), dada sesak (26.7\%), sulit tidur (23.3\%), dan nafsu makan menurun (15.6\%). Rata-rata lama keluhan yang dirasakan contoh adalah sepanjang hari. Sepertiga contoh mengalami keluhan dengan intensitas $\leq 5$ menit setiap kali keluhan tersebut terasa. Pada pengukuran tekanan darah sistolik dan diastolik, hampir dari setengah contoh mengalami hipertensi $(45.5 \%)$ yang tersebar menjadi hipertensi tahap $1(20 \%)$ dan hipertensi tahap $2(25.5 \%)$.

Hasil uji korelasi Spearman menunjukkan bahwa aktivitas sehari-hari, kebiasaan olahraga, kebiasaan merokok, konsumsi alkohol, konsumsi suplemen, jamu dan tanaman obat tidak berkorelasi dengan tekanan darah sistolik dan diastolik. Hal ini dapat disebabkan oleh adanya faktor lain yang sangat menentukan tekanan darah yaitu pola makan (masukan sodium dan kalium).

Hasil uji korelasi Spearman menunjukkan bahwa kebiasaan olahraga contoh berkorelasi negatif terhadap sakit pinggang $(p<0.05)$. Konsumsi suplemen berkorelasi positif dengan keluhan susah buang air besar $(p<0.01)$. Konsumsi jamu berkorelasi positif dengan usia $(p<0.01)$ dan berkorelasi negatif dengan nyeri pinggang $(p<0.05)$. Konsumsi tanaman obat berkorelasi positif dengan menurunnya nafsu makan $(p<0.01)$, susah mengunyah $(p<0.01)$, 
dan menurunnya indera penciuman dan perasa $(p<0.01)$.

\section{DAFTAR PUSTAKA}

BPS. 2004. Statistik Penduduk Usia Lanjut (Survei Sosia Ekonomi Nasional), BPS, Jakarta.

Darmojo. 2000. Demografi san Epidemiologi Populasi Lanjut Usia. Dalam Darmojo\& Martono (Eds), Geriatri (Ilmu Kesehatan Usia Lanjut) (hlm 35-55). Balai Penerbit FKUI, Jakarta.

Gedif T \& Hanh HJ. 2003. The use of medical plants in self care in rural central Ethiopia. Journal of Ethnopharmacology, 87, 155-161.

Handayani L. 2002. Pemanfaatan obat tradisional untuk kesehatan lansia. Jurnal Kedokteran dan Farmasi Medika, 11, 736738.

Hurlock EB. 1999. Psikologi Perkembangan suatu Pendekatan Sepanjang Rentang Kehidupan. Erlangga, Jakarta.
Jamal S. 2006. Pria desa berpendidikan rendah, perokok terbanyak. Jurnal Kedokteran dan Farmasi, 33, 152-155.

Kiongdo G. 1997. Penatalaksanaan faktor-faktor resiko kardiovaskular pada penderita hipertensi. Jurnal Kedokteran dan Farmasi Medika, 9, 599-602.

Mursito B. 2004. Sehat Di Usia Lanjut Dengan Ramuan Tradisional. Penebar Swadaya, Jakarta.

Oswari E. 1997. Menyongsong Usia Lanjut dengan Bugar dan Bahagia. Pustaka Sinar Harapan, Jakarta.

Sheps SG. 2005. Mayo Clinic Hipertensi, Mengatasi Tekanan Darah Tinggi. PT Duta Prima, Jakarta.

Takasihaeng J. 2000. Hidup Sehat di Usia Lanjut. Kompas, Jakarta.

Wirakususmah ES. 2000. Tetap bugar di Usia Lanjut. Trubus Agriwidya, Jakarta. 